\title{
NEW DATA ON THE ROLE OF MADZHAR IN GOLDEN HORDE TRADE OF SKIN AND LEATHER PRODUCTS: ARCHEOZOOLOGICAL ASPECT ${ }^{1}$
}

\author{
Liliya V. Yavorskaya \\ Institute of Archaeology of the Russian Academy of Sciences, Moscow, Russian Federation
}

\begin{abstract}
Documentary sources on Italian sea trade of the $13^{\text {th }}-14^{\text {th }}$ centuries report about the export of large volumes of animal skins and processed leathers from the Golden Horde. A significant problem was the finding out places of slaughtering livestock and processing raw materials of animal origin by archaeological methods, since organic remains are not preserved in the cultural layers of settlements and cities of the Golden Horde. The article analyzes three collections of animal bones from archaeological excavations in the craftsmen's quarter of the Golden Horde city of Madzhar during 2014-2017. In the 2014 year's collection at excavation site no. X (10), where the master of bone carving lived, a fact of special selection of goat and ram horns for products being manufactured of their horn covers was identified, aside from production wastes of a dense horn. In pit no. 2 (2016), an archaeozoological research has revealed a specific anatomical set of domestic ungulates remains: shattered heads and distal parts of the legs, which can be formed only as a result of massive slaughter of livestock to obtain skins. At excavation site no. XIII of 2017, archaeozoological research was able to record not only a specific anatomical set, but also traces of the use of small cattle bones in leather processing devices, which, combined with the archaeological context, made it possible to identify the presence of a specialized seasonal leather workshop on this site. It was established that cattle was slaughtered right in the cities, as well as artisans processed the obtained skins on specially equipped seasonal workshop sites. Thus, archaeozoological research showed that Madzhar, like other cities, participated in the production of animal skins and leather, which subsequently became the most important export products of the Golden Horde state.
\end{abstract}

Key words: The Golden Horde, the city of Madzhar, archaeozoological analysis, anatomical set of bone residues, leather production, export of animal skin.

Citation. Yavorskaya L.V., 2020. New Data on the Role of Madzhar in Golden Horde Trade of Skin and Leather Products: Archeozoological Aspect. The Lower Volga Archaeological Bulletin, vol. 19, no. 1, pp. 202-210. (in Russian). DOI: https://doi.org/10.15688/nav.jvolsu.2020.1.11

\section{НОВЫЕ ДАННЫЕ О РОЛИ МАДЖАРА В ЗОЛОТООРДЫНСКОЙ ТОРГОВЛЕ ШКУРНО-КОЖЕВЕННОЙ ПРОДУКЦИЕЙ: АРХЕОЗООЛОГИЧЕСКИЙ АСПЕКТ ${ }^{1}$}

\section{Лилия Вячеславовна Яворская}

Институт археологии РАН, г. Москва, Российская Федерация

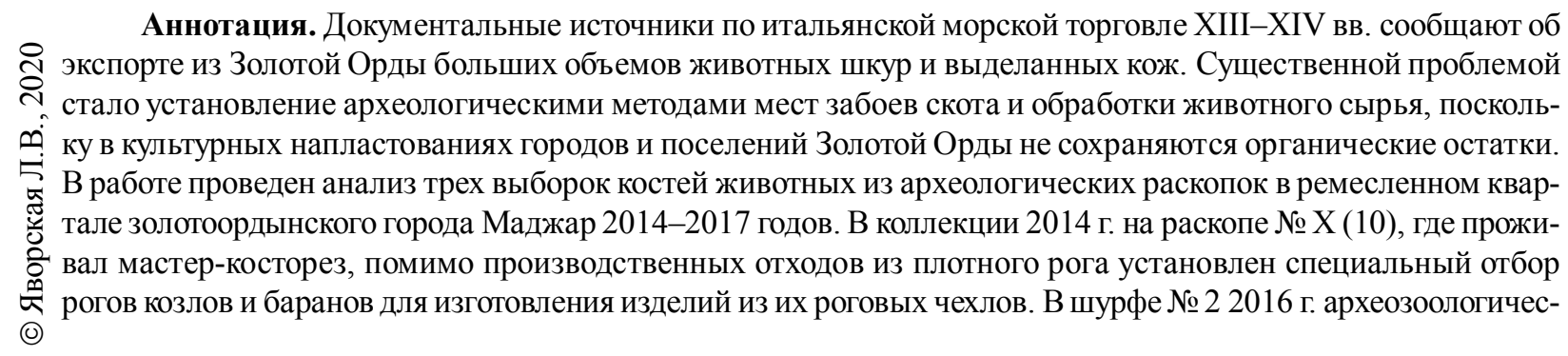


кое исследование выявило специфичный анатомический набор остатков рогатого скота: разломанные головы и дистальные части конечностей, который может образоваться исключительно при массовых забоях скота для получения шкур. На раскопе № XIII 2017 г. археозоологическим исследованием удалось зафиксировать не только специфичный анатомический набор, но и следы использования костей мелкого рогатого скота в приспособлениях для обработки кож, что в совокупности с археологическим контекстом позволило установить факт наличия на этом участке специализированной сезонной кожевенной мастерской. Выяснено, что именно в городах производился забой скота для получения шкур, здесь же ремесленники обрабатывали полученные шкуры на специально оборудованных сезонных площадках-мастерских. Таким образом, археозооологическим исследованием установлено, что Маджар, как и другие города, участвовал в производстве животных шкур и кож, которые впоследствии становились важнейшей экспортной продукцией золотоордынского государства.

Ключевые слова: Золотая Орда, город Маджар, археозоологический анализ, анатомический набор костных остатков, кожевенное производство, экспорт животной кожи.

Цитирование. Яворская Л. В., 2020. Новые данные о роли Маджара в золотоордынской торговле шкурно-кожевенной продукцией: археозоологический аспект // Нижневолжский археологический вестник. Т. 19, № 1. C. 202-210. DOI: https://doi.org/10.15688/nav.jvolsu.2020.1.11

Большинство городов Золотой Орды располагалось на сухопутных и водных путях, обеспечивая трансконтинентальные торговые маршруты защитой и вливая в товарные потоки ремесленную продукцию собственного производства. Торговые пути в степном Предкавказье сходились в городе Маджар, возникшем на рубеже XIII-XIV веков. Арабский путешественник Ибн Баттута, побывавший здесь в 1330-х гг., указывает на значительные размеры города, разноэтничное население, множество базаров и ремесел [СМИЗО, 1887, c. 287-288]. Недавними археологическими исследованиями были выявлены напластования разных периодов в истории Маджара в течение XIV в., но наибольшая интенсивность накопления находок, означающая взлет городской жизни и ремесленных производств, пришлась на слои, датирующиеся 1330-1350 гг. [Бочаров и др., 2018a, с. 404]. Следы различных ремесленных производств - керамического, металлургического, стеклодельного, косторезного и многих других, продукция которых широко расходилась по торговым путям Евразии, отчетливо фиксируются при раскопках археологами золотоордынских городов. Помимо них хорошо известно о важнейшей и очень доходной статье золотоордынского экспорта - шкурах животных [Еманов, 2018, c. 68-71]. Из серии документов, регулирующих итальянскую морскую торговлю, известно, что в конце XIII - начале XIV в. вывозились в больших объемах выделанные и невыделанные шкуры рогатого скота и лошадей [Бочаров, Масловский, 2015, с. 7]. В 1330- 1350-х гг. ханское правительство проводит ряд протекционистских мер, делая невыгодным для итальянцев вывоз невыделанных шкур [Бочаров, Масловский, 2015, с. 7-8], что должно было способствовать увеличению количества и объемов ремесленных производств, обрабатывающих шкуры животных. Источники умалчивают о местоположении таких мастерских - проводился ли забой, а также обработка шкур и кож в кочевьях или в городах. Поскольку остатки-отходы подобных производств являются остатками органическими, их следы весьма непросто обнаружить в культурных напластованиях золотоордынских памятников с сухим культурным слоем, где органика не сохраняется [Бочаров, Масловский, 2015 , с. 7]. Тем не менее при помощи методов археозоологии можно зафиксировать остатки массовых забоев скота, которые имеют весьма специфичный видовой и анатомический набор, а также следы манипуляций с тушами [Яворская, 2019, с. 581]. Цель данного исследования состоит в представлении именно таких остатков с городища Маджары, из раскопок которого за последние шесть лет проанализированы все археозоологические коллекции и выявлено несколько комплексов костных остатков, которые правильно было бы назвать производственными.

Городище Маджары, являющееся остатками золотоордынского города Маджар, расположено в Буденновском районе Ставропольского края, восточнее г. Буденновска, его площадь составляет около 110 га. Руслом реки Кума город разделен на две неравные части, 
и большую правобережную часть его на настоящий момент занимают земли сельскохозяйственного назначения, где преимущественно и проводятся археологические исследования [Бочаров и др., 2018a, с. 404].

В 2014 г. в торгово-ремесленной части города экспедицией государственного унитарного предприятия «Наследие» Министерства культуры Ставропольского края заложен раскоп, получивший по общей нумерации раскопов на городище № X (10). В нескольких горизонтах в хронологических рамках XIV в. были обнаружены остатки жилого дома и предшествовавшей ему крупной полуземлянки, зафиксированной как яма № 1, имевшей, скорее всего, производственное назначение. Это сооружение и синхронные ямы вокруг нее при перепланировке данного участка города были засыпаны культурным слоем со всем его содержимым. Вокруг этого комплекса обнаружены другие ямы небольших размеров, использование которых, как и хронология, повидимому, было различным. Общий объем остеологической коллекции с данного раскопа составил 4135 единиц [Яворская, Антипина, 2017, с. 248]. Кости характеризуются хорошей (4 балла) естественной сохранностью, что позволило определить основную массу фрагментов до уровня класса, а млекопитающих - до вида. Судя по следам искусственного воздействия, основную часть коллекции составляют «кухонные» остатки [Яворская, Антипина, 2017, с. 248], однако есть и другие категории археозоологических материалов, которые более верно было бы атрибутировать как «производственные отходы».

Основу этой категории остатков составляют фрагменты костной основы рогов полорогих и плотнорогих парнокопытных со следами раскроя и обработки. Обработанные обломки стержней рогов принадлежат четырем видам: домашним баранам и козлам (Ovis aries и Capra hircus), преимущественно самцам, а также диким парнокопытным - благородному оленю (Cervus elaphus) и арменийскому (или закавказскому) муфлону (Ovis gmelini gmelini). От представителя последнего вида происходит один крупный фрагмент черепа - междурожье с целыми костными стержнями рогов [Яворская, Антипина, 2017, рис. 2]. От диких копытных в данной коллек- ции оказались только рога, других частей скелета не было. Среди производственных остатков наиболее многочисленными были раскроенные-распиленные костные стержни рогов мелкого рогатого скота (96\%, см. табл. 1). Они встречены в трех ямах (№ 1, 2 и 5), но основная масса обнаружена в нижних слоях ямы № 1 (см. табл. 1), здесь же находился и фрагмент черепа муфлона.

Подобные остатки - обрубленные или отпиленные костные стержни рогов полорогих копытных - чаще всего маркируют изъятие и использование в качестве сырья только их роговых чехлов, и потому они считаются ремесленными отходами. Остатки рогов оленя благородного также несут на себе следы ремесленного раскроя, представляя собой сырьевые остатки, а роговые стержни муфлона сохранились полностью лишь потому, что красивые роговые чехлы были, скорее всего, использованы для изготовления питьевых или охотничьих рогов и необходимо было их аккуратное снятие целыми с рогового стержня.

Само распределение «производственных» остатков по культурным напластованиям и объектам показывает, что на раннем этапе функционирования данного участка города (в пределах 1330-1350-х гг.) здесь работал мастер-косторез, который использовал в качестве сырья плотный рог и роговые чехлы мелкого рогатого скота. Совершить отбор большого количества пригодных для изделий рогов козлов и баранов возможно было лишь при массовых забоях скота.

Непосредственные результаты массовых забоев скота обнаружены при археозоологическом исследовании обширной коллекции костных остатков, полученной в 2016 г. из шурфа № 2. В 2015-2017 гг. исследования на памятнике проводились археологической экспедицией «Каффа» Института археологии им. А.Х. Халикова Академии наук Республики Татарстан при участии Краеведческого музея села Прасковея [Бочаров и др. 2018б, c. 31]. По общей нумерации были исследованы раскопы № XI, XII, XIII и два шурфа (№ 1, 2). Трехлетними планомерными работами экспедицией получены новые данные по топографии и стратиграфии Маджара, уточнено назначение отдельных районов города, сохранность ряда объектов монумен- 
Л.В. Яворская. Новые данные о роли Маджара в золотоордынской торговле шкурно-кожевенной продукцией

Таблица 1. Видовой состав и распределение в культурных напластованиях остатков рогов парнокопытных со следами обработки. Городище Маджары. Раскоп № X (10) 2014 года

Table 1. The species composition and distribution in the cultural strata of the remains of the horns of small cattle with traces of processing. Madzhar settelment. Excavation no. X (10) 2014

\begin{tabular}{|c|c|c|c|c|c|c|}
\hline \multirow[b]{2}{*}{ Слои, объекты } & \multirow{2}{*}{$\begin{array}{c}\text { Определимые } \\
\text { кости млеко- } \\
\text { пигающих }\end{array}$} & \multicolumn{4}{|c|}{ Фрагменты рогов, абсолютное число } & \multirow{2}{*}{$\begin{array}{c}\% \text { рогов от } \\
\text { определимых } \\
\text { костей млеко- } \\
\text { питающих } \\
\end{array}$} \\
\hline & & MPC & Олень & Муфлон & Всего & \\
\hline \multicolumn{7}{|c|}{ Культурный слой } \\
\hline Пласт 1-2 & 491 & 2 & & & 2 & 0,4 \\
\hline Пласт 3 & 419 & & & & & \\
\hline Пласт 4-5 & 275 & 5 & & & 5 & 1,8 \\
\hline \multicolumn{7}{|c|}{ Заполнение ям } \\
\hline Яма 1, верх & 396 & 55 & 1 & & 56 & 14,1 \\
\hline Яма 1, низ & 1393 & 158 & 1 & 1 & 160 & 11,5 \\
\hline Яма 2 & 35 & 4 & & & 4 & 11,4 \\
\hline Яма 3 & 143 & & 6 & & 6 & 4,2 \\
\hline Яма 4 & 78 & & & & & \\
\hline Яма 5 & 200 & 17 & 1 & & 18 & 9,0 \\
\hline Яма 6 & 27 & & & & & \\
\hline Яма 7 & 99 & & & & & \\
\hline Яма 8 & 39 & & & & & \\
\hline Яма 9 & 130 & & & & & \\
\hline Яма 10 & 44 & & & & & \\
\hline $\begin{array}{l}\text { Всего по слою } \\
\text { и ямам }\end{array}$ & 3769 & 241 & 9 & 1 & 251 & 6,7 \\
\hline$\%$ & & 96,0 & 3,6 & 0,4 & 100,0 & \\
\hline
\end{tabular}

тальной архитектуры [Бочаров и др. 2018б, c. 31].

Шурф № 2 заложен на восточном участке в центральной части городища в 860 м восточнее поймы реки Кумы в 190 м северовосточнее от раскопа № XII [Бочаров и др., 2018б, с. 33]. Площадь шурфа была небольшой -4 кв. м, но на нем зафиксирована очень высокая концентрация костных остатков 2246 фрагментов, что почти вдвое больше, чем на раскопе № XII того же 2016 г. площадью 16 кв. м (1 373 фрагмента). Культурные напластования, выявленные в шурфе, датируются в пределах 1330-1360-х годов. Сохранность костных остатков хорошая - 4 балла по пятибалльной шкале. На некоторых костях встречены следы какого-то кристаллического вещества цвета ржавчины, возможно остатки специальной обработки органических отходов. Степень раздробленности костных фрагментов в этой коллекции оказалась невысокой - 18-30 фрагментов в 1 куб. дм. Набор таксонов в археозоологической коллекции из шурфа № 2 обычен для Маджара, но остеологический спектр показал отличия от бытового накопления «кухонных» остатков: очень высокую долю (88 \%) в нем составили кости мелкого рогатого скота, а в анатомическом наборе этого вида заметно преобладали кости двух отделов скелета - разломанные остатки голов и самые нижние дистальные отделы конечностей - метаподии и фаланги (см. рис. 1).

Подобный набор обнаружен в скоплениях другого крупного золотоордынского города Азака, расположенного на Нижнем Дону [Яворская, Масловский, 2018, с. 372], и маркирует остатки забоев в «производственных» целях - для снятия шкуры особым способом, когда предварительно отсекаются голова и ноги животного [Яворская, 2019, с. 558].

Из обзора этих двух коллекций понятно, что в золотоордынском городе Маджар в 1330-1360-х гг. проводились массовые забои скота с целью получения шкур. Археозоологическое исследование коллекции с раско- 


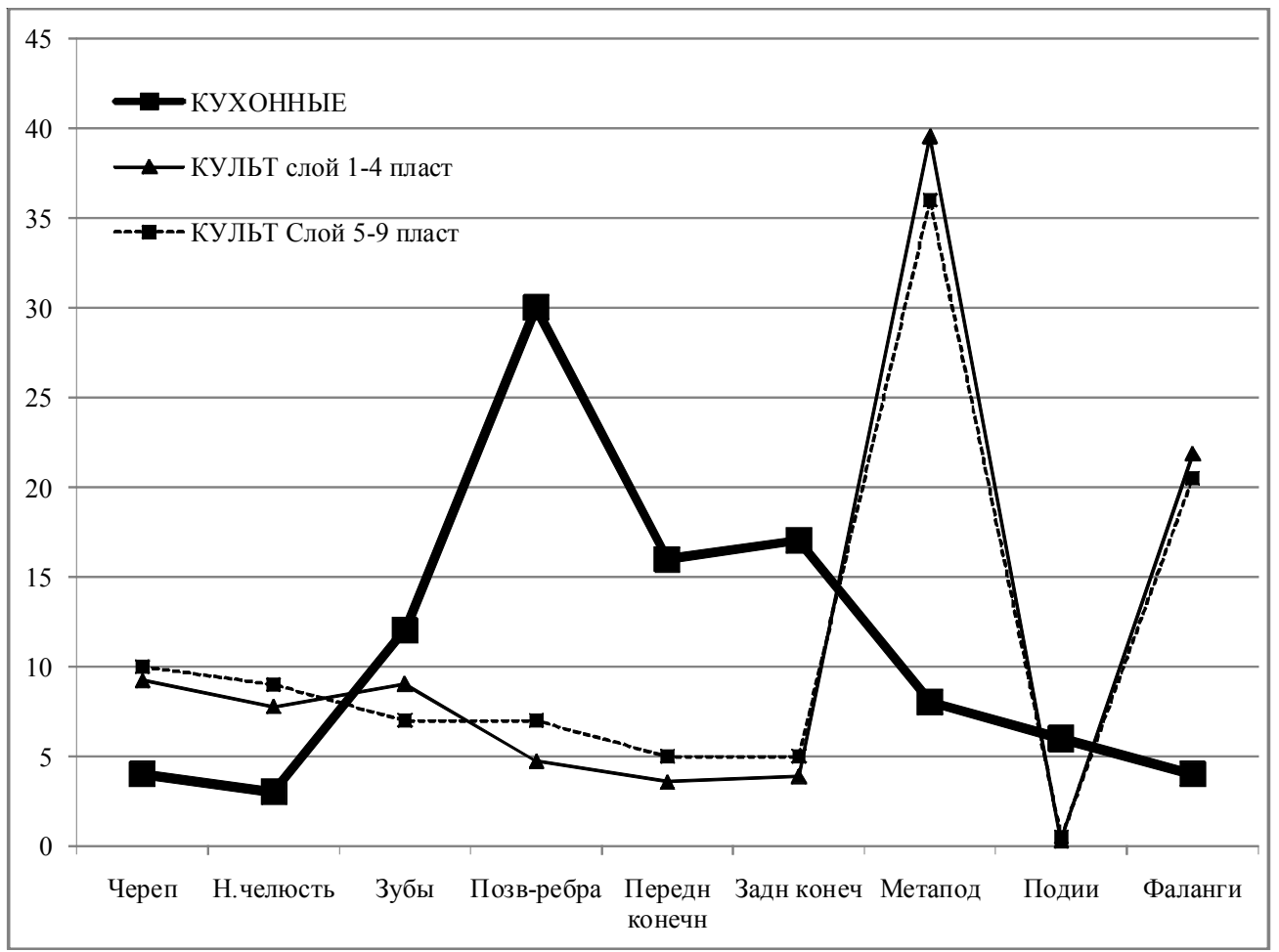

Рис. 1. Распределение костных остатков в анатомическом наборе мелкого рогатого скота. Городище Маджары (шурф № 2, 2016 год)

Fig. 1. The distribution of bone residues in the anatomical set of small cattle. Madzhar settlement (pit no. 2, 2016)

Примечание. Под графом «кухонные» имеется в виду распределение анатомического набора одной туши рогатого скота в категории «кухонные остатки».

па № XIII 2017 г. достроило картину участия ремесленников города в импорте животных шкур и изделий из них.

Раскоп № XIII 2017 г. был заложен на территории бывшего торгово-ремесленного квартала в южной части большого поля в 500 м восточнее поймы реки Кумы. Площадь исследуемого участка составила 48 кв. метров. Верхний стратиграфический распахиваемый горизонт (слой I, пласты 1-3) относится к напластованиям XX - начала XXI в., в котором встречены переотложенные находки золотоордынского времени. Ниже расположен слой II (пласты 4-6) - основной средневековый культурный слой на данном участке, который датируется 1310-1340 годами. К этому слою относятся выявленные на раскопе сооружения 1 и 2. Сооружение 1 представляло собой вымостку из фрагментированных и бракованных обожженных кирпичей местного маджарского производства. Вымостка хорошо датируется монетными и керамическими находками в рамках 1330-х гг. [Бочаров, Явор- ская, 2019, с. 189]. Сооружение 2, зафиксированное в северо-западной части раскопа на уровне 5 пласта, представляло собой выкопанную в материке узкую траншею глубиной около 1 м, с отвесными стенками и ровным дном, ориентированную по линии юго-запад - северо-восток [Бочаров, Яворская, 2019, рис. 5]. Стратиграфическая ситуация и находки в заполнении траншеи позволяют утверждать, что она синхронна сооружению 1 и составляет с ним единый комплекс. В северо-западном углу раскопа в квадрате A1 выделялся участок, который по заполнению отличался от основного культурного слоя: на 5-м и 6-м пластах до уровня материка здесь зафиксирована прослойка черного плотного грунта с включениями кирпичной крошки и высокой концентрацией костных остатков - около 500 фрагментов на 1 кв. м культурного слоя, мощностью до $50 \mathrm{~cm}$. Это заполнение также синхронно сооружениям 1 и 2.

Коллекция костных остатков хорошей сохранности составила 3343 фрагмента, рас- 
сматривалась по выборкам в соответствии с археологическим контекстом. Отдельными выборками стали материалы из культурного слоя (пласты 4-6), из заполнения над вымосткой-сооружением 1 , из заполнения траншеи сооружения 2, а также из специфичного заполнения прослойки культурного слоя в квадрате А1 в пластах 5-6. Всего получилось 4 отдельных, но вполне представительных выборки [Бочаров, Яворская, 2019, табл. 2]. Степень раздробленности костей в данной коллекции не превышает показателей, обычных для Маджара - 20-27 фрагментов в 1 куб. дм. Таксономический набор костных остатков также обычен для Маджарского городища, основную роль в нем играют остатки домашних «мясных» млекопитающих, преимущественно крупного рогатого скота (далее КРС; 50 \% от всех определимых домашних видов), мелкого рогатого скота (далее - МРС; его доля несколько превышает $30 \%$ в разных выборках) и лошади (доля - 14-17 \% по разным выборкам). Необычность заполнения прослойки в квадрате A1 на пластах 5 и 6 подтвердилась и анализом археозоологических материалов из нее - здесь выявлено 497 фрагментов, то есть, в пределах одного квадрата культурного слоя на двух пластах сосредоточена шестая часть всей коллекции. Основную массу этого заполнения, около $60 \%$, составляли кости МРС. Доля остатков КРС оказалась здесь ниже обычной - около $36 \%$, а доля костей лошади составила около $4 \%$ [Бочаров, Яворская, 2019, табл. 3].

Наиболее необычным в остеологической коллекции с этого раскопа оказался анатомический набор многочисленных видов крупного и мелкого рогатого скота. По распределению анатомических частей скелетов видно, что во всех выборках «завышены» в 3-10 раз доли остатков голов и нижних челюстей КРС и в 10 раз - нижних челюстей МРС по отношению к стандартной разделке одной туши. Доли таких анатомических частей, как метаподии обоих видов животных, существенно завышены: для КРС в 4-5 раз, для МРС - в 8-11 раз [Бочаров, Яворская, 2019, табл. 3]. В заполнении прослойки в квадрате A1 оказались самые высокие накопления метаподиев мелкого рогатого скота, превышающие обычные показатели в 18 раз. Некоторое пре- вышение «стандарта» накопления можно наблюдать для лопаток и лучевых костей КРС, а также плечевой, лучевой и берцовой кости МРС [Бочаров, Яворская, 2019, табл. 3].

Выявленный анатомический набор по двум видам рогатого скота показывает, что преимущественно археозоологическую коллекцию составляют вовсе не «кухонные» костные остатки. Вновь перед нами остатки масштабных забоев крупного и мелкого рогатого скота, причем кроме обычных отчленений голов и дистальных частей конечностей перед снятием шкуры при разделке туши вычленялись еще некоторые кости. Кроме разломанных остатков черепов, все остальные вышеуказанные наименования костей обоих видов рогатого скота, показатели по которым «завышены», традиционно использовались в косторезном деле. На малопригодных для поделок метаподиях и других трубчатых костях мелкого рогатого скота, на диафизах обнаружены особые следы - характерная «залощенность» по одной стороне трубки [Бочаров, Яворская, 2019, с. 195, рис. 8]. На этих же костях обнаружены грубо прорезанные отверстия в одном из эпифизов (верхнем или нижнем торцевом конце кости), другой конец, как правило, сломан. Косточки с такими следами маркируют инструментарий кожевников. Они входили в состав сложных приспособлений, служили «валиками» для выпрямления нешироких кожаных лент. Для закрепления в устройстве в проксимальном конце метаподиев проделывались отверстия, верхний слой компакты в этой части кости, как правило, сильно стерт. Между жестко закрепленными костными «валиками» протягивались кожаные ленты, и вследствие этой процедуры на одной стороне диафиза кости появлялось характерное «лощение». По-видимому, для подобных мастерских было необходимо множество таких трубчатых вставок, поскольку сломавшуюся кость в приспособлении заменяли на новую, близкую по размеру. Наиболее удобными костями в этих приспособлениях, по-видимому, были метаподии, поскольку их больше всех сохранилось в культурных напластованиях данного раскопа. Однако и другие трубчатые кости из скелета МРС, близкие по размеру, вычленяли из туши при разделке и тоже использовали в таких устройствах. Находки 
костей с «лощением» составляют от 10 до 30 \% по выборкам от всей совокупности костей МРС [Бочаров, Яворская, 2019, с. 196], и, таким образом, они фиксируют уже не просто происходивший поблизости забой животных, но и снятие шкур, последующую за этим разделку туш, вычленение отдельных костей и, самое важное, первичную обработку кожевенной продукции.

Исходя из имеющегося видового набора костных остатков и специфики анатомического набора костей многочисленных видов в данной археозоологической коллекции, а также из анализа следов на костных фрагментах становится возможной интерпретация выявленных на раскопе необычных синхронных сооружений - кирпичной площадки-вымостки (сооружения № 1) и глубокой узкой траншеи (сооружения № 2). Вымостку из фрагментов обычных и бракованных кирпичей возможно интерпретировать как сезонную производственную площадку, где мог происходить забой животных, могли раскладываться шкуры, стоять раскроечные столы и быть установлены специальные приспособления для вытягивания-выпрямления кожаных лент. Сооружение № 2 - траншея, скорее всего, использовалась как ванна для вымачивания шкур, сгонки волоса, других первичных процессов их обработки.

Обнаруженная мастерская, скорее всего, носила комплексный характер: здесь наблюдаются разные фазы производственного цикла от забоя животных до изготовления продукции из их шкур. Собственно забои и работа подобных производственных площадок не были постоянно действующим предприятием. Скорее всего, они эпизодически возобновлялись, возможно, в определенные сезоны.

Для археологии и реконструкции палеоэкономики Золотой Орды важны как находка мастерской, так и археозоологическая атрибуция скоплений однотипных костных остатков как «производственных» сбросов. Они показывают, что аккумуляция скота для забоя происходила, скорее всего, вблизи городов. Забой и первичная выделка шкур проводились в городских мастерских, на специально оборудованных площадках. На основании письменных документов можно было лишь предполагать наличие мастерских, занимавшихся выделкой животных шкур, неясными оставались места их расположения и характер работы. Проведенное археозоологическое исследование позволяет утверждать основную роль сезонных городских мастерских в массовом производстве животных шкур и кож - важнейшей статьи государственного экспорта Золотой Орды.

\section{ПРИМЕЧАНИЕ}

${ }^{1}$ Исследование выполнено при поддержке РФФИ, проект № 20-09-00310 «Археозоологические материалы как источник для реконструкции палеоэкономических процессов в лесной и степной зонах Восточной Европы в XII-XVI вв.».

The research was completed by the RFBR, project no. 20-09-00310 "Archaeozoological materials as a source for the reconstruction of paleo-economic processes in the forest and steppe zones of Eastern Europe in the XII-XVI centuries".

\section{СПИСОК ЛИТЕРАТУРЫ}

Бочаров С. Г., Масловский А. Н., 2015. Письменные источники об итальянской торговле кожей в Северном Причерноморье и данные археологии // Ученые записки Казанского университета. Серия: Гуманитарные науки. Т. 157, кн. 3. С. 7-11.

Бочаров С. Г., Обухов Ю. Д., Ситдиков А. Г., 2018а. Золотоордынский город Маджар в системе культурных связей Евразии. По материалам новых археологических исследований (2015-2017 гг.) // Кавказ в системе культурных связей Евразии в древности и средневековье. XXX “Крупновские чтения” по археологии Северного Кавказа": материалы Междунар. науч. конф. Карачаевск : Карачаево-Черексский государственный университет. С. 404-406.

Бочаров С. Г., Обухов Ю. Д., Ситдиков А. Г., 2018б. Три года археологических исследований золотоордынского города Маджар (2015-2017). Итоги и перспективы // Археология евразийских степей. № 5. C. 31-38. 
Бочаров С. Г. Яворская Л. В., 2019. К вопросу о кожевенном производстве в Золотой Орде: результаты археологического и археозоологического исследования на городище Маджары в 2017 году // Поволжская археология. № 4 (30). С. 184-199. DOI: https://doi.org/10.24852/pa2019.4.30.184.199.

Еманов А. Г., 2018. Между полярной звездой и полуденным солнцем. Кафа в мировой торговле XIII-XV веков. СПб. : Алетея. $386 \mathrm{c.}$

СМИЗО, 1887. Сборник материалов, относящихся к истории Золотой Орды. В. Тизенгаузен. Т. 1. СПб. 571 с.

Яворская Л. В., 2019. Скопления костей животных в городах Золотой Орды: основные находки, видовой состав, анатомический набор // Генуэзская Газария и Золотая Орда. Т. 2. Казань ; Кишинев : Stratum plus. C. 553-567.

Яворская Л. В., Антипина Е. Е., 2017. Золотоордынский город Маджар: первые результаты исследования археозоологической коллекции из ремесленного квартала (раскоп X (10) - 2014 г.) // Аналитические исследования лаборатории естественнонаучных методов. Вып. 4. М. : Ин-т археологии РАН. С. 245-252.

Яворская Л. В., Масловский А. Н., 2018. Находки скоплений костей животных в золотоордынском Азаке: видовой состав, анатомический набор, топография // Историко-археологические исследования в Азове и на Нижнем Дону в 2014-15 гг. Вып. 30. Азов : Азовский музей-заповедник. С. 358-378.

\section{REFERENCES}

Bocharov S.G., Maslovskiy A.N., 2015. Pis'mennye istochniki ob ital'yansko torgovle kozhey v Severnom Prichernomor'e i dannye arheologii [Written Sources about the Italian Leather Trade in the Northern Black Sea Region and Archaeological Data]. Uchenye zapiski Kazanskogo universiteta. Seriya: Gumanitarnye nauki [Scientific Bulletin of the Kazan University. Series: Humanities], vol. 157, book 3, pp. 7-11.

Bocharov S.G., Obuhov Yu.D., Sitdikov A.G., 2018a. Zolotoordynskiy gorod Madzhar v sisteme kul'turnyh svyazey Evrazii. Po materialam novyh arheologicheskih issledovaniy (2015-2017 gg.) [The Golden Horde City of Madzhar in the System of Cultural Relations of Eurasia. Based on New Archaeological Research (2015-2017)]. Kavkaz v sisteme kul 'turnyh svyazey Evrazii v drevnosti i srednevekov'e. XXX "Krupnovskie chteniya" po arheologii Severnogo Kavkaza": materialy Mezhdunar. nauch. konf. [The Caucasus in the System of Cultural Relations of Eurasia in Antiquity and the Middle Ages. XXX "Krupnov readings" on Archaeology of the North Caucasus". Proceedings of the International Scientific Conference]. Karachaevsk, KarachayCherkess State University, pp. 404-406.

Bocharov S.G., Obukhov Yu.D., Sitdikov A.G., 20186. Tri goda arheologicheskih issledovaniy zolotoordynskogo goroda Madzhar (2015-2017). Itogi i perspektivy [Three Years of Archaeological Study of Golden Horde Town Madzhar (2015-2017). Results and Prospects]. Arkheologiya Evraziiskikh stepei [Archaeology of Eurasian Steppes], no. 5, pp. 31-38.

Bocharov S.G., Yavorskaya L.V., 2019. K voprosu o kozhevennom proizvodstve v Zolotoy Orde: rezul'taty arheologicheskogo i arheozoologicheskogo issledovaniya na gorodishche Madzhary v 2017 godu [On the Question of Leather Production in the Golden Horde: Results of Archaeological and Archaeozoological Research in the Madzhar Settlement in 2017]. Povolzhskaya arkheologiya [The Volga River Region Archaeology], vol. 30, no. 4, pp. 184-199. DOI: http://doi.org/10.24852/pa2019.4.30.184.199.

Emanov A.G., 2018. Mezhdu polyarnoy zvezdoy i poludennym solntsem. Kafa v mirovoy torgovle XIII-XV vekov [Between the Polar Star and Midday Sun. Cafa in the World Trade of $13^{\text {th }}-15^{\text {th }}$ Centuries]. Saint Petersburg, Aleteya Publ. 386 p.

SMIZO, 1887. Sbornik materialov, otnosyashchihsya k istorii Zolotoy Ordy, V. Tizengauzen [A Collection of Materials Related to the History of the Golden Horde. V. Tiesenhausen], vol. 1. St. Petersburg. 571 p.

Yavorskaya L.V., 2019. Skopleniya kostey zhivotnyh v gorodah Zolotoy Ordy: osnovnye nahodki, vidovoy sostav, anatomicheskiy nabor [Concentrations of Animal Bones in the Cities of the Golden Horde: Main Finds, Species, Anatomical Set]. Genuezskaia Gazariia i Zolotaia Orda [The Genoese Gazaria and the Golden Horde], vol. 2. Kazan; Kishinev, Stratum Plus, pp. 553-567.

Yavorskaya L.V., Antipina E.E., 2017. Zolotoordynskiy gorod Madzhar: pervye rezul'taty issledovaniya arheozoologicheskoy kollektsii iz remeslennogo kvartala (raskop X (10) - 2014 g.) [The Golden Horde City of Madzhar: the First Results of the Study of the Archaeozoological Collection from the Handicraft District (Excavation X (10) - 2014)]. Analiticheskie issledovaniia laboratorii estestvennonauchnykh metodov [Analytical Studies of the Laboratory of Natural Scientific Methods], iss. 4. Moscow, IA RAS, pp. 245-252. 
L.V. Yavorskaya. New Data on the Role of Madzhar in Golden Horde Trade of Skin and Leather Products

Yavorskaya L.V., Maslovskiy A.N., 2018. Nahodki skopleniy kostey zhivotnyh v zolotoordynskom Azake: vidovoy sostav, anatomicheskiy nabor, topografiya [Finds of Concentrations of Animal Bones in the Golden Horde Azak: Species Composition, Anatomical Set, Topography]. Istoriko-arkheologicheskie issledovaniia v Azove i na Nizhnem Donu v 2014-2015 gg. [Historical and Archaeological Research in Azov and Lower Don Region in 2014-2015], iss. 30. Azov, Azov Historical-Archaeological and Palaeontological Museum-Reserve, pp. 358-378.

\section{Information About the Author}

Liliya V. Yavorskaya, Candidate of Sciences (History), Associate Professor, Senior Researcher, Laboratory of the Natural Scientific Methods in Archaeology, Institute of Archaeology of the Russian Academy of Sciences, Dmitriya Ulyanova St., 19, 117036 Moscow, Russian Federation, Lv.yavorskaya@gmail.com, https://orcid.org/0000-0002-5272-7442

\section{Информация об авторе}

Лилия Вячеславовна Яворская, кандидат исторических наук, доцент, старший научный сотрудник лаборатории естественнонаучных методов в археологии, Институт археологии РАН, ул. Дмитрия Ульянова, 19, 117036 г. Москва, Российская Федерация, Lv.yavorskaya@gmail.com, https://orcid.org/0000-0002-5272-7442 